\title{
The Nature of Hyperactivity in Children and Adolescents with Hydrocephalus: A Test of the Dual Pathway Model
}

\author{
Jim Stevenson and Ineke Pit-ten Cate \\ School of Psychology, University of Southampton, \\ Highfield, Southampton, England SO17 1BJ
}

SUMMARY

To determine the strength and nature of the association between hydrocephalus and hyperactivity and to test the dual pathway model (DPM) of AD/HD, we compared a group of 51 children and adolescents with hydrocephalus with 57 normally developing controls from the general population on a battery of neuropsychological assessments. The mean hyperactivity scores were significantly greater in the group with hydrocephalus (effect size $=0.94$ ). This association was not just part of a general elevated rate of behavior problems and was not affected by sex or age. Variation in the clinical features of hydrocephalus was not related to the severity of hyperactivity. Path analysis was used to examine the relation between IQ, delay aversion, and executive function. In accordance with the DPM, the effect of hydrocephalus on hyperactivity was completely mediated via delay aversion and executive functions.

\section{KEY WORDS}

hyperactivity, delay aversion, executive function hydrocephalus, dual pathway model

Reprint requests to: Prof. Jim Stevenson, School of Psychology, University of Southampton, Highfield, Southampton SO17 1BJ; e-mail: jsteven@soton.ac.uk

\section{INTRODUCTION}

Hydrocephalus is a neurological condition that occurs when there is an abnormal accumulation of cerebrospinal fluid within the ventricles and/or the subarachnoid space of the brain. Hydrocephalus causes raised intracranial pressure and can distort the surrounding brain tissue. The condition can result from an overproduction of cerebrospinal fluid, an obstruction of the cerebrospinal fluid flow, or a failure of the structures of the brain to reabsorb the fluid. Hydrocephalus can be present at birth (congenital hydrocephalus) or acquired after birth from a variety of causes. Hydrocephalus can be caused by spina bifida but is also associated with other conditions such as meningitis and premature birth. The effects of hydrocephalus on child functioning vary considerably and depend on the areas of the brain most affected. These effects can include impaired fine motor skills, executive functioning, learning, attention, and behavior (Tew, 1991).

There is evidence that children with hydrocephalus are at increased risk of range of behavioral problems. Some studies suggest that only when hydrocephalus is associated with mental retardation is an increase found in such behaviors as hyperactivity (Fernell et al., 1991a) and autistic-like behavior (Fernell et al., 1991b). A more recent study, however, has suggested that a wide range of children with hydrocephalus are at risk of elevated behavior problem scores (Fletcher et al., 1995). This 
study also demonstrated that the behavior problems (particularly those related to attention) were more common in more severely affected hydrocephalic children amongst a sample of very low birth weight infants $(<1750 \mathrm{~g})$ (Fletcher et al., 1997).

These studies therefore indicate that a particular feature of the behavioral profile in children with hydrocephalus is the presence of hyperactivity. This is a behavioral style characterized by inattention, impulsivity, and overactivity (Taylor, 1999). Children with a pervasive and enduring extreme high level of hyperactivity are designated as showing attention deficit/hyper-activity disorders (AD/HD) (Swanson et al., 1998). It has been postulated that $\mathrm{AD} / \mathrm{HD}$ can develop as a condition either as a consequence of executive dysfunction arising from disturbances in the fronto-dorsal striatal circuit or of delay aversion arising from altered reward processes stemming from alterations in the fronto-ventral striatal circuits (Sonuga-Barke, 2002; Sonuga-Barke, 2004 - this issue).

The presence of high levels of hyperactivity in children with hydrocephalus provides an opportunity to test the generalizability of the dual pathway model (DPM) of $\mathrm{AD} / \mathrm{HD}$. The aim of this paper is to establish whether dysfunctions in delay aversion and in executive function present separate but coacting influences on the development of hyperactivity in children with hydrocephalus. If so, the results would be a demonstration that the DPM can account for the behavior of children with hyperactivity arising as a secondary consequence of brain damage, as well as for children in the general population for whom genetic factors are seen to play the primary etiological role (Kuntsi \& Stevenson, 2000).

\section{EXPERIMENTAL}

\section{Participants}

The samples were obtained in two parallel studies. For the Child Study (6-12 years), the following numbers of children completed the study: 20 children with spina bifida only, 31 children with hydrocephalus only, 16 children with spina bifida and hydrocephalus combined, 30 normally developing children, and 31 children born prematurely (defined here as less than 32 weeks gestation). For the Adolescent Study (13-18 years) the following numbers of children completed the study: 9 adolescents with spina bifida only, 20 adolescents with hydrocephalus only, 20 adolescents with spina bifida and hydrocephalus combined, and 27 normally developing adolescents.

The following inclusion criteria were applied for participants in the Child and Adolescent Studies:

1. English must be the child's first language

2. They must not have marked vision or hearing impairments

3. They must have a developmental age of approximately 6 years or above.

4. There should be no co-morbidity with brain tumors

5. Co-morbidity with meningitis or cerebral palsy should be allowed only if criteria 2 and 3 are met.

An invitation letter was sent to families attending clinics in the South of England requesting their participation in the study. The letter explained that a follow-up phone call would be made to them during the next week to arrange a convenient time if they were willing to take part. Families of children in the general population sample were obtained through contact with local schools. Information was sent out in school newsletters and interested families contacted us to arrange an appointment.

\section{Measures}

Executive function. The CANTAB is a computerized battery of tests of separate aspects of cognitive functioning related to executive 
function. The psychometric properties of the CANTAB are well established and it is becoming widely adopted with children (Luciana, 2003).

In this study, 9 of the 11 subtests were used: Motor Screening (MOT), Stockings of Cambridge (SOC), Spatial Working Memory (SWM), Reaction Time (RTI), Paired Associates Learning (PAL), Pattern Recognition Memory (PRM), Spatial Recognition Memory (SRM), Big/Little Circle (BLC), and Intra/Extra-dimensional Shift (IED).

A discriminant function analysis was used to obtain a weighted aggregate of the scores on the subtests of the CANTAB that best predicted high scores (6 or more) on the SDQ Hyperactivity scale: Attention-Intra/Extra dimensional shift, Reaction time; Visual memory-Pattern recognition memory, Spatial recognition memory, Paired associate learning; Working memory and planningStockings of Cambridge, Spatial working memory.

Delay Aversion Task. This task uses a computer to present a game in which the child has to destroy enemy spacecraft by the child clicking on the mouse. The aim was to score as many points as possible and to motivate the child, the tester tells the child that (s)he will receive a small prize (a pen) at the end. For each of the 20 trials, the child has to choose between a small immediate reward (which gives a score of one point) and a delayed reward (score of three points). The test-re-test reliability of the measure has been found to be good (Kuntsi et al., 2001). For the present analysis, the tester's ratings of the child's behavior whilst waiting for the delayed reward (on a three-point scale) were used as an index of aversion to delay.

$I Q$. The following four sub-tests of the WISCIII R (Wechsler, 1992) were used to obtain a prorated full-scale IQ: comprehension, information, block design, and picture completion.

Hyperactivity. Hyperactivity was measured based on the parent's report. The parents completed the Strengths and Difficulties Questionnaire (Goodman, 1997). This questionnaire is a wellvalidated measure that includes a hyperactivity subscale that provides a score for the degree of hyperactivity shown by the child.

\section{RESULTS}

\section{What is the degree of hyperactivity associated with hydrocephalus?}

The mean score for participants with hydrocephalus and normally developing controls on the four sub-scales of the SDQ are presented in Table 1.

TABLE 1

a) Mean SDQ score for participants with hydroephalus and for normally developing controls

\begin{tabular}{|l|c|c|c|c|}
\hline \multirow{2}{*}{$\begin{array}{c}\text { Dependent } \\
\text { variable }\end{array}$} & \multicolumn{2}{|c|}{$\begin{array}{c}\text { Hydrocephalus } \\
\mathrm{N}=51\end{array}$} & \multicolumn{2}{c|}{$\begin{array}{c}\text { Controls } \\
\mathrm{N}=58\end{array}$} \\
\cline { 2 - 5 } & Mean & $\mathrm{SD}$ & Mean & $\mathrm{SD}$ \\
\hline $\begin{array}{l}\text { Conduct } \\
\text { problems }\end{array}$ & 2.45 & 2.07 & 1.60 & 1.71 \\
\hline $\begin{array}{l}\text { Emotional } \\
\text { symptoms }\end{array}$ & 3.61 & 2.79 & 1.54 & 1.82 \\
\hline $\begin{array}{l}\text { Peer } \\
\text { problems }\end{array}$ & 3.57 & 2.59 & 1.30 & 1.61 \\
\hline Hyperactivity & 4.98 & 3.11 & 2.65 & 2.47 \\
\hline
\end{tabular}

b) Summary of MANOVA

\begin{tabular}{|l|c|c|c|c|c|c|}
\hline \multirow{2}{*}{$\begin{array}{l}\text { Dependent } \\
\text { variable }\end{array}$} & \multicolumn{3}{|c|}{ No. covariates } & \multicolumn{3}{c|}{ With covariates } \\
\cline { 2 - 7 } & $\begin{array}{c}\text { Mean } \\
\text { square }\end{array}$ & $\mathrm{F}$ & $\mathrm{p}$ & $\begin{array}{c}\text { Mean } \\
\text { square }\end{array}$ & $\mathrm{F}$ & $\mathrm{P}$ \\
\hline $\begin{array}{l}\text { Conduct } \\
\text { problems }\end{array}$ & 19.65 & 5.51 & $<.02$ & 5.77 & 2.99 & $\mathrm{~ns}$ \\
\hline $\begin{array}{l}\text { Emotional } \\
\text { symptoms }\end{array}$ & 114.67 & 21.09 & $<.001$ & 13.92 & 3.19 & $\mathrm{~ns}$ \\
\hline $\begin{array}{l}\text { Peer } \\
\text { problems }\end{array}$ & 138.75 & 30.61 & $<.001$ & 24.87 & 8.45 & $<.004$ \\
\hline Hyperactivity & 146.29 & 18.82 & $<.001$ & 29.40 & 6.35 & $<.01$ \\
\hline
\end{tabular}


There were significant differences between the groups for each of the subscales. To test whether there were specific behavioral problems, we repeated the ANOVA with the other three subscales as covariates. With this analysis, the effects of hydrocephalus on conduct and emotional problems were no longer significant. Nevertheless, both hyperactivity and peer problems remained as showing a significant excess of problems in the participants with hydrocephalus.

Is the degree of hyperactivity the same for hydrocephalus alone and for hydrocephalus with spina bifida?

The above result compared participants with hydrocephalus alone with normally developing controls. Table 2 shows that in participants with hydrocephalus associated with spina bifida, the hyperactivity scores are significantly greater than those in normally developing controls. In addition, participants who were born prematurely also have significantly elevated levels of hyperactivity. Although the effect of hydrocephalus on hyperactivity is similar for hydrocephalus alone and hydrocephalus plus spina bifida, the subsequent analyses were restricted to the hydrocephalus alone participants to test for effects using a more etiologically homogeneous group.

Does this association remain when the effects of premature birth are taken into account?

Because hydrocephalus can be associated with premature birth, this finding raises the possibility that it is not hydrocephalus but premature birth that carries the risk of later hyperactivity. Accordingly, an analysis of the effects of prematurity and of hydrocephalus on the mean hyperactivity scores for children under the age of 12 years (prematurely born adolescents were not included in the study) is presented in Table 3 . The children with hydrocephalus are divided into those
TABLE 2

Comparison of the effects of condition on mean SDQ hyperactivity scores

\begin{tabular}{|c|c|c|c|c|}
\hline \multicolumn{2}{|l|}{ Condition } & $\mathrm{N}$ & Mean & SD \\
\hline \multicolumn{2}{|c|}{ Spina bifida (S) } & 29 & 3.66 & 2.87 \\
\hline \multicolumn{2}{|c|}{ Hydrocephalus (H) } & 51 & 4.98 & 3.11 \\
\hline \multicolumn{2}{|c|}{$\begin{array}{l}\text { Spina bifida }+ \\
\text { Hydrocephalus }(\mathrm{S}+\mathrm{H})\end{array}$} & 36 & 4.31 & 2.18 \\
\hline \multicolumn{2}{|c|}{ Premature $(\mathrm{P})$} & 31 & 4.03 & 2.98 \\
\hline \multicolumn{2}{|c|}{ Controls (C) } & 57 & 2.65 & 2.47 \\
\hline Factor & $\mathrm{df}$ & $\begin{array}{l}\text { Mean } \\
\text { Square }\end{array}$ & $\mathbf{F}$ & $\mathrm{p}$ \\
\hline Condition & 4 & 39.204 & 5.25 & $<.001$ \\
\hline Error & 199 & 7.473 & & \\
\hline
\end{tabular}

Planned contrasts - compared to Controls

\begin{tabular}{|l|c|c|c|}
\hline Condition & $\begin{array}{c}\text { Effect } \\
\text { size }^{\mathrm{a}}\end{array}$ & $\mathrm{T}$ & $\mathrm{p}$ \\
\hline Spina bifida (S) & 0.41 & 1.61 & $\mathrm{~ns}$ \\
\hline Hydrocephalus (H) & 0.94 & 4.42 & $<.001$ \\
\hline $\begin{array}{l}\text { Spina bifida }+ \\
\text { Hydrocephalus (S+H) }\end{array}$ & 0.67 & 2.85 & $<.005$ \\
\hline Premature (P) & 0.56 & 2.27 & $<.024$ \\
\hline
\end{tabular}

a (Condition mean - Control mean )/ Control SD

TABLE 3

Comparison of the effects of hydrocephalus and prematurity on mean SDQ hyperactivity scores

\begin{tabular}{|l|c|c|c|c|}
\hline Group & $\mathrm{N}$ & Mean & SD \\
\hline $\begin{array}{l}\text { Premature } \\
\text { Hydrocephalus }\end{array}$ & 10 & 4.90 & 3.41 \\
\hline Term Hydrocephalus & 20 & 5.20 & 3.37 \\
\hline Premature & 31 & 4.03 & 2.98 \\
\hline Term Controls & 30 & 3.00 & 2.74 \\
\hline \multicolumn{5}{|c|}{} \\
\hline Factor & df & $\begin{array}{c}\text { Mean } \\
\text { Square }\end{array}$ & F & P \\
\hline Hydrocephalus (h) & 1 & 43.65 & 4.72 & $<.033$ \\
\hline Prematurity (P) & 1 & 2.49 & 0.27 & ns \\
\hline Hx P & 1 & 8.23 & 0.89 & ns \\
\hline Error & 87 & 9.25 & & \\
\hline
\end{tabular}


with and without a premature birth and compared in a $2 \times 2$ ANOVA with prematurely born children and normally developing controls. It can be seen that only the hydrocephalus factor is significant.

\section{Does this relate to other origins of hydrocephalus?}

Hydrocephalus has a number of possible causes. The participants with hydrocephalus were divided into four groups according to the origin of their condition: intracranial hemorrhage $(n=21)$, meningitis $(n=7)$, other $(n=11)$, not known $(n=$ 11). There were no significant differences between these four groups in the mean SDQ hyperactivity scores $(F(3,46)=0.18, n s)$.

Does this relate to the clinical features of hydrocephalus?

A number of features of the presentation of hydrocephalus might be related to the degree of hyperactivity shown. These include the presence of a shunt, undergoing a third ventriculostomy, occurrence of fits, association with cerebral palsy and visual difficulties, including squints and nystagmus. For each of these clinical features, the participants were divided into those with the feature and those without. A series of independent sample t-tests were conducted with the SDQ hyperactivity score as the dependent variable. In no case was the mean significantly different for those with or those without these clinical features.

\section{Is there any evidence of moderators such as sex or age?}

Two $2 \times 2$ ANOVAs were conducted to establish whether sex and age respectively interact with the presence of hydrocephalus to influence levels of hyperactivity. For both sex [Sex $(F(1,104)$ $=0.06, p=.802)$, Hydrocephalus $(F(1,104)=17.39$, $\mathrm{p}<.001)$, Sex $x$ Hydrocephalus $(F(1,104)=0.02$, $\mathrm{p}=.883)]$ and age $[$ Age $(F(1,104)=1.77, \mathrm{p}=.187)$,

\section{TABLE 4}

Correlation between cognitive measures and SDQ hyperactivity in hydrocephalus and control children

\begin{tabular}{|l|c|c|c|c|}
\hline & IQ & EFDS & $\begin{array}{c}\text { Delay } \\
\text { aversion }\end{array}$ & SDQH \\
\hline IQ & 1.00 & & & \\
\hline EFDS & $-.45^{* *}$ & 1.00 & & \\
\hline $\begin{array}{l}\text { Delay } \\
\text { aversion }\end{array}$ & -.07 & .08 & 1.00 & \\
\hline SDQH & $-.30^{*}$ & $.43^{* *}$ & $.43^{* *}$ & 1.00 \\
\hline
\end{tabular}

EFDS - EF discriminant score; SDQH - SDQ hyperactivity hydrocephalus $(\mathrm{N}=28)$, controls $(\mathrm{N}=28)$

${ }^{*} \mathrm{p}<.05,{ }^{* *} \mathrm{p}<01$

Hydrocephalus $(F(1,104)=17.41, p<.001)$, Age $x$ Hydrocephalus $(F(1,104)=0.01, p=.976)]$, there were neither significant main effects nor interactions between hydrocephalus and these factors.

\section{Psychological correlates of hyperactivity in the} hydrocephalus and in control samples

The above analyses have shown that hydrocephalus is associated with elevated levels of hyperactivity, regardless of other associated clinical characteristics of the child. The DPM suggests that both cognitive (executive function abilities) and motivation (delay aversion) will be related to the degree of hyperactivity. Table 4 presents the correlations between these plus IQ and the SDQ hyperactivity score for the combined hydrocephalus and control samples. It can be seen that hyperactivity is significantly correlated with each of these three measures. Executive functioning and IQ are significantly correlated but neither correlates significantly with delay aversion. This pattern of correlations provides initial support for the notion that cognitive and motivational 


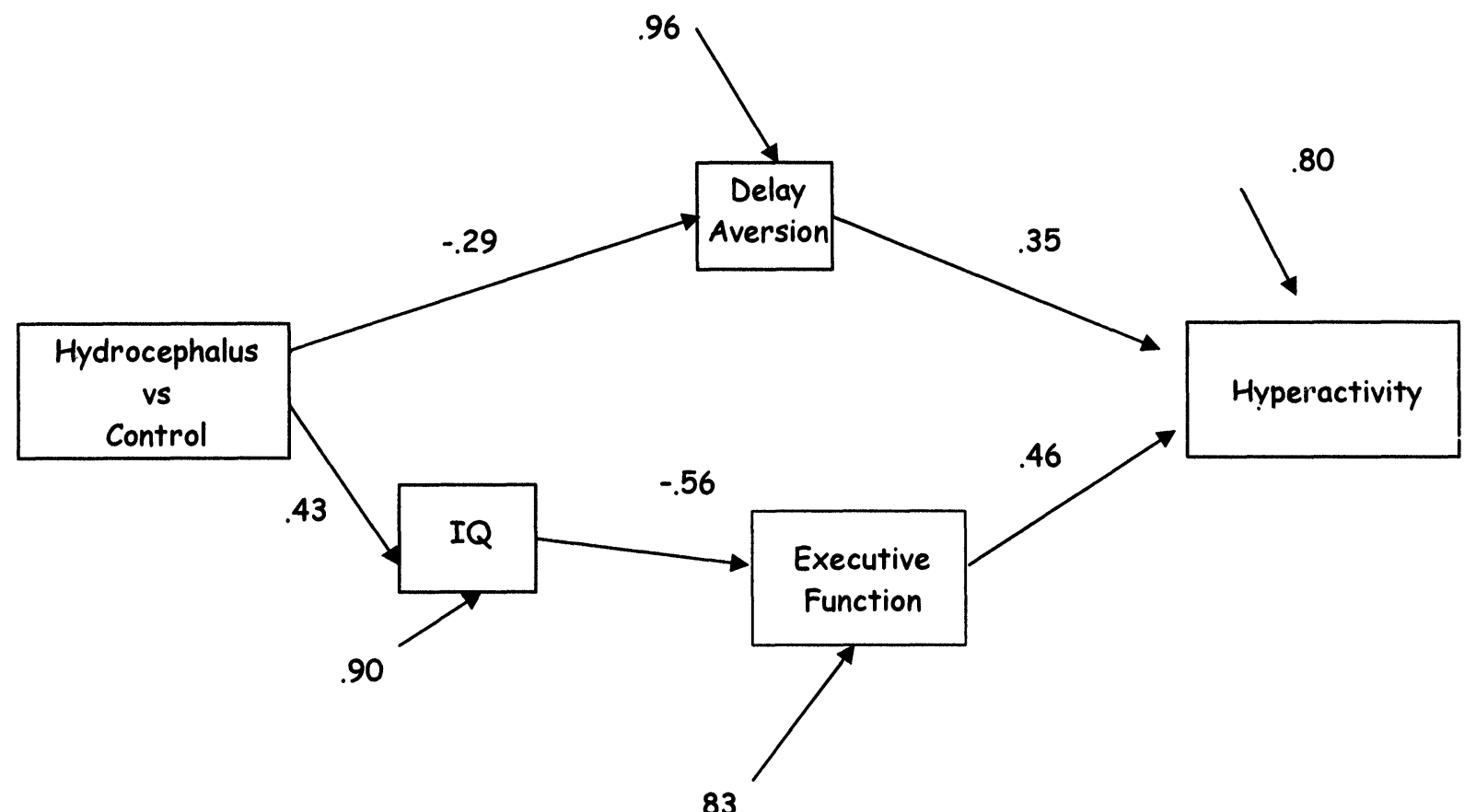

Final model : $\chi^{2}(5, N=60)=5.21, n s ; C F I=1.00 ; R M S E A=0.03\left(C I_{.90} 0.00\right.$ to 0.18$)$

Fig. 1: The dual pathway model fitted to the relationships between hydrocephalus and hyperactivity

characteristics are independent predictors of hyperactivity. This possibility is investigated more systematically in the following path analysis.

\section{A path model of the influence of cognitive factors on hyperactivity}

The dual pathway model (DPM) predicts that the delay aversion and executive function measures are independent predictors of hyperactivity. Accordingly, a path model was developed that allows hydrocephalus to have both direct effects on hyperactivity and two separate indirect effects, mediated via delay aversion and executive function.
The correlations reported above indicated that the executive function influence on hyperactivity might in part be a function of a more general cognitive effect on behavior. The IQ measure was therefore introduced as a possible mediator of the effect of hydrocephalus on executive function. It is also possible that IQ mediates some of the effects of hydrocephalus on delay aversion. The DPM explicitly excludes the possible impact of executive function on delay aversion and vice versa. This path model was fitted to the variance/ covariances between the variables and the final model retaining all the significant paths and no other is presented in Fig. 1. 
As predicted by the DPM, hyperactivity is the product of two independent pathways. The effect of hydrocephalus on hyperactivity is equally divided between two pathways. One indirect route mediated via delay aversion $(.35 \times-.29=-.10)$ and a second mediated via IQ and executive function $(.43 \times-.56 \times .46=-.11)$. Importantly, the model does not require paths linking the motivational and cognitive routes to achieve a good fit to the data.

\section{DISCUSSION}

The DPM was developed to explain the findings in studies of children with $\mathrm{AD} / \mathrm{HD}$ showing a series of consistent and well replicated deficits in both motivational aspects of task engagement (delay aversion) and in executive function and state regulation. We have shown previously that these two components influencing hyperactivity might reflect different etiological factors. State regulation (shown for example by high variance in reaction times) carries genetic influences on ADHD. Delay aversion, on the other hand, can carry some of the environmental influences on ADHD (Kuntsi \& Stevenson, 2001).

The studies from which the DPM was developed are based on the general population or on referred samples without established neurological deficits. The present paper aimed to extend the testing of the DPM to hyperactivity that arises from frank neurological damage arising from hydrocephalus. The findings show that in this group of children and adolescents, hyperactivity is a relatively specific behavioral deficit that is not moderated by gender or age. The origins of hydrocephalus and the clinical characteristics of the participants were not related to the degree of hyperactivity shown. Children and adolescents with hydrocephalus are, as a group, at risk of elevated hyperactivity.
The pattern of cognitive and motivational deficits associated with hyperactivity in this sample was similar to those in the referred and general population samples mentioned above. Individual differences in executive function and in delay aversion were significantly related to the level of hyperactivity shown. These two factors accounted for the elevated rate of hyperactivity in children and adolescents with hydrocephalus, i.e. once the differences between normally developing controls and children/adolescents with hydrocephalus were taken into account, there was no longer a direct effect of hydrocephalus on hyperactivity. Within the neurologically compromised sample, the risk of hyperactivity was accounted for by two independent routes-one via motivational factors reflecting delay aversion and the second via executive dysfunction.

The findings therefore represent support for the DPM and for its general applicability to diverse groups at risk for elevated levels of hyperactivity. There are, however, a number of limitations with the data presented in this paper. The first is that the number of children and adolescents meeting the criteria for ADHD were too few to use this measure as the dependent variable in the analyses. Nevertheless, there is good evidence that ADHD can be very appropriately characterized as the extreme of a continuum of degrees of hyperactivity (Gjone et al., 1996; Levy et al., 1997).

The second limitation was that although there were a number of indicators of executive dysfunction, we used only a single measure of delay aversion. It would be important to replicate these findings with a wider range of delay aversion indicators.

Third, although we have shown that the DPM can account for the elevated levels of hyperactivity in children and adolescents with hydrocephalus, the generalizability of the DPM needs to be examined in other groups having a high risk of 
ADHD or with elevated levels of hyperactivity. One such group comprises children raised in institutional settings whose behavioral profiles arise from adverse early experiences. There is evidence from children born in the U.K. (Hodges \& Tizard, 1989) and Romania (Kreppner et al., 2001) that institutional rearing carries an increased risk of hyperactivity. It would be of considerable interest to establish whether the DPM can also account for elevated rates of hyperactivity in children with these early averse experiences.

These limitations do not detract from the conclusion that for children and adolescents with hydrocephalus, their levels of hyperactivity arise from the same two pathways that are responsible for hyperactive behavior in the general population. It appears that DPM is a powerful but parsimonious account of the processes within the child that lead to hyperactive patterns of behavior.

\section{ACKNOWLEDGMENTS}

We would like to express out thanks to the families and to the children and adolescents that took part in this research for their willing participation. We had excellent cooperation from teachers in local schools, both in identifying control subjects and in providing information on their behavioral and educational development. The authors would like to acknowledge the contribution to the study made by Jane Wilkinson, Gemma Buckle, and Aine Fulcher in testing and interviewing and by Teresa Rivers in giving administrative support. We are grateful to clinicians at Southampton General, Princess Anne, and John Radcliffe Hospitals for assistance with identifying suitable families for the study. Dr. Colin Kennedy provided valuable guidance on the neurological aspects of the study. The study was funded by research grants from the Association for Spina Bifida and Hydrocephalus.

\section{REFERENCES}

Fernell E, Gillberg C, Vonwendt L. 1991a. Behavioralproblems in children with infantile hydrocephalus. Dev Med Child Neurol 33: 388-395.

Fernell E, Gillberg C, Vonwendt L. 1991b. Autistic symptoms in children with infantile hydrocephalus. Acta Paediatr Scand 80: 451-457.

Fletcher JM, Brookshire BL, Landry SH, Bohan TP, Davidson KC, Francis DJ, et al. 1995. Behavioral adjustment of children with hydrocephalus: Relationships with etiology, neurological, and family status. J Pediatr Psychol 20: 109-125.

Fletcher JM, Landry SH, Bohan TP, Davidson KC, Brookshire BL, Lachar D, et al. 1997. Effects of intraventricular hemorrhage and hydrocephalus on the long-term neurobehavioral development of preterm very-low-birthweight infants. Dev Med Child Neurol 39: 596-606.

Gjone H, Stevenson J, Sundet, J.M. 1996. Genetic influence on parent-reported attention-related problems in a Norwegian general-population twin sample. J Am Acad Child Adolesc Psychiatry 35: 588-596.

Goodman R. 1997. The strengths and difficulties questionnaire: a research note. 38: 581-586.

Hodges J, Tizard B. 1989. IQ and behavioraladjustment of ex-institutional adolescents. J Child Psychol Psychiatry 30: 53-75.

Kreppner JM, O'Connor TG, Rutter M. 2001. Can inattention/overactivity be an institutional deprivation syndrome? J Abnorm Child Psychol 29 : 513-528.

Kuntsi J, Stevenson J. 2001. Psychological mechanisms in hyperactivity: II The role of genetic factors. $\mathbf{J}$ Child Psychol Psychiatry 42: 211-220.

Kuntsi J, Stevenson J, Oosterlaan J, Sonuga-Barke EJS. 2001. Test-retest reliability of a new delay aversion task and executive function measures. $\mathrm{Br}$ J Dev Psychol 19: 339-348.

Kuntsi J, Stevenson J. 2000. Hyperactivity in children: A focus on genetic research and psychological theories. Clin Child Fam Psychol Rev 3: 1-23.

Levy F, Hay DA, McStephen M, Wood C, Waldman I. 1997. Attention-deficit hyperactivity disorder: A category or a continuum? Genetic analysis of a large-scale twin study. J Am Acad Child Adolesc Psychiatry 36: 737-744.

Luciana M. 2003. Practitioner review: Computerized assessment of neuropsychological function in 
children: Clinical and research applications of the Cambridge Neuropsychological Testing Automated Battery (CANTAB). J Child Psychol Psychiatry 44: 649-663.

Sonuga-Barke EJ. 2002. Psychological heterogeneity in $\mathrm{AD} / \mathrm{HD}$; $\mathrm{A}$ dual pathway model of behaviour and cognition. Behav Brain Res 130: 29-36.

Sonuga-Barke EJS. 2004. The dual pathway model of $\mathrm{AD} / \mathrm{HD}$; an elaboration of neuro-developmental characteristics. Neural Plasticity 11: 23-28.

Swanson JM, Sergeant JA, Taylor E, Sonuga-Barke EJ, Jensen PS, Cantwell DP. 1998. Attention- deficit hyperactivity disorder and hyperkinetic disorder. Lancet 351 (9100): 429-433.

Taylor E. 1999. Developmental neuropsychopathology of attention deficit and impulsiveness. Dev Psychopathol 11: 607-628.

Tew B. 1991. The effects of spina bifida and hydrocephalus upon learning and behaviour. In: Bannister CM, Tew B, eds, Current concepts in Spina Bifida \& Hydrocephalus. Oxford, UK: Mac Keith; 158-179.

Wechsler DA. 1991. Wechsler Intelligence Scale for Children-Third Edition (WISC-III). San Antonio, Texas, USA: The Psychological Corporation. 

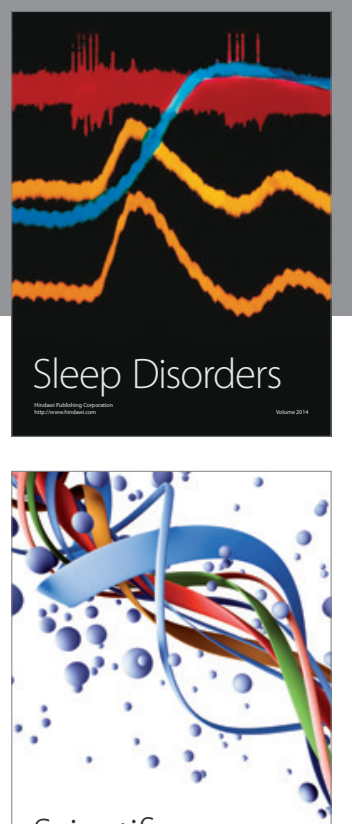

Scientifica
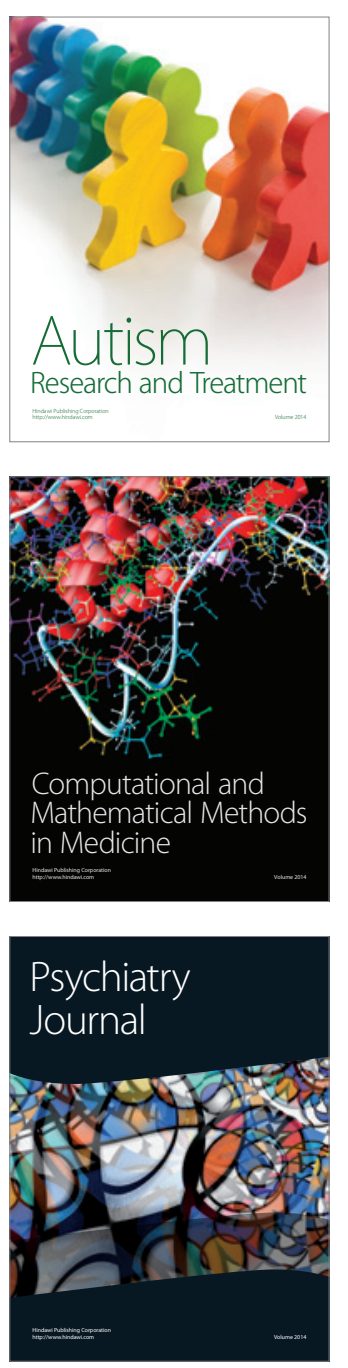
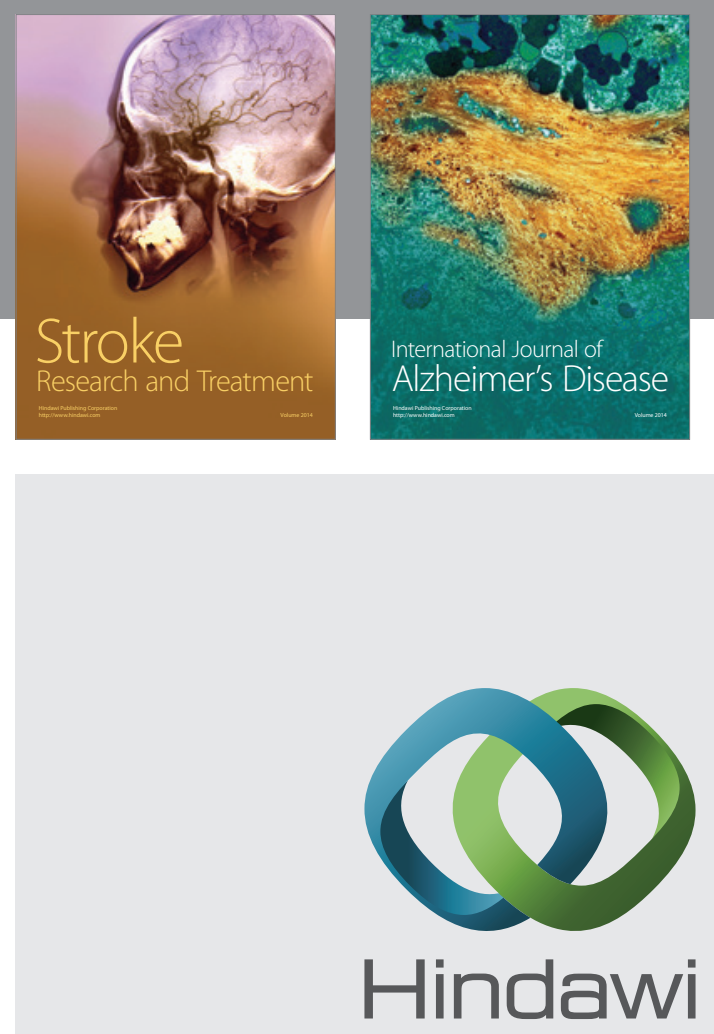

Submit your manuscripts at

http://www.hindawi.com
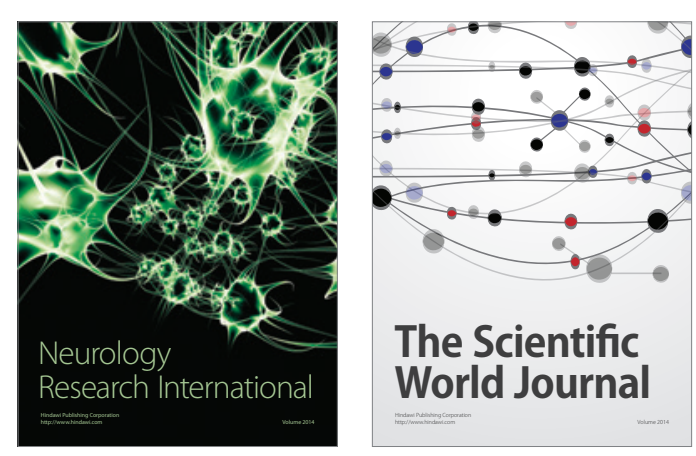

The Scientific World Journal

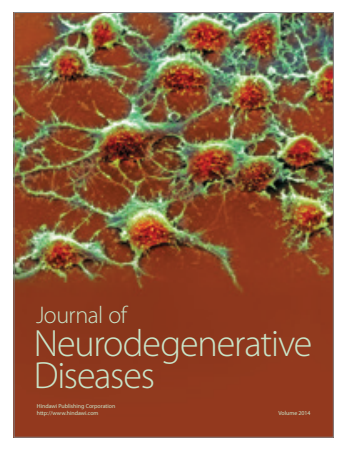

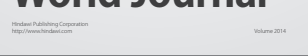

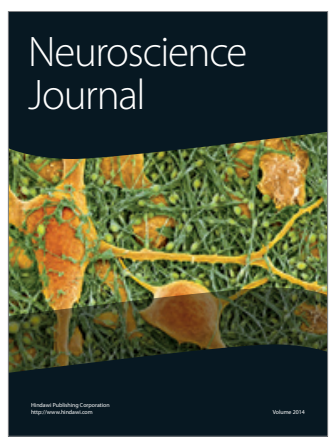

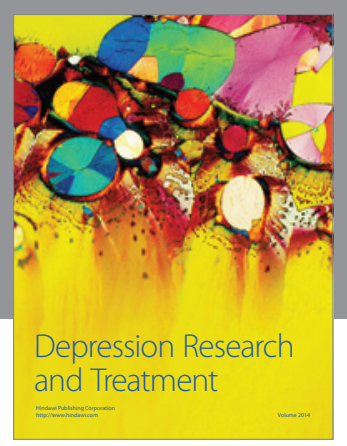
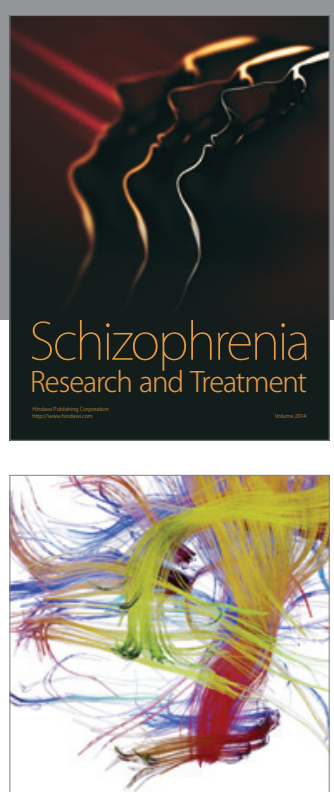

Brain Science

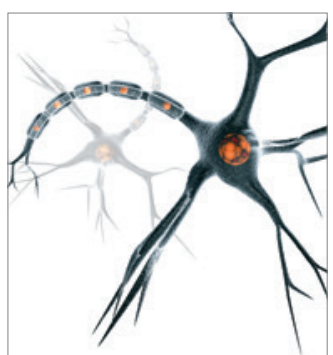

Neural Plasticity
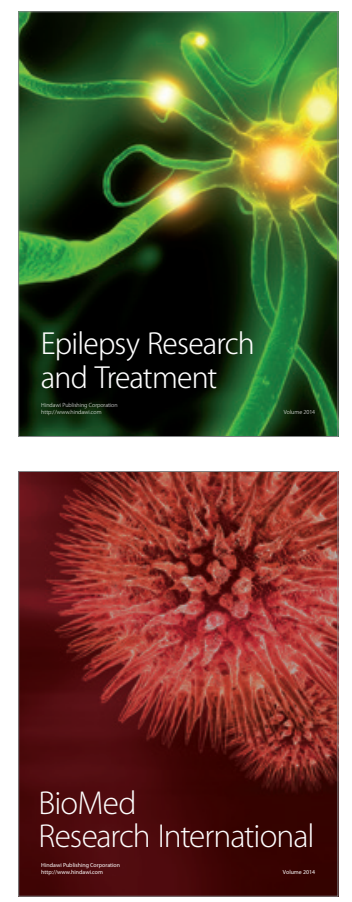

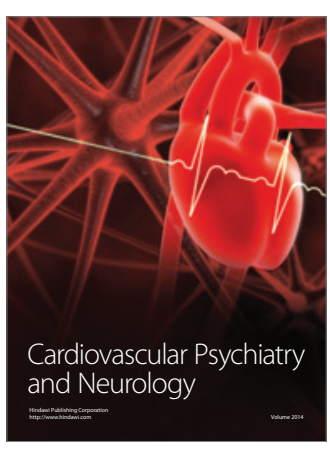

Parkinson's

Disease
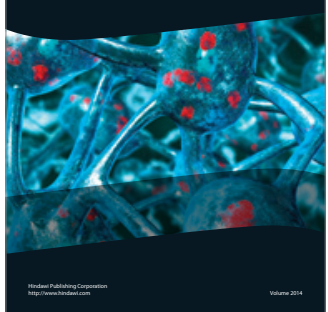